\title{
Differential Regulation of Liver P-450III Cytochromes in Choline-deficient Rats: Implications for the Erythromycin Breath Test as a Parameter of Liver Function
}

\author{
Joseph C. Kolars, Scot't A. Mlrkay, Ken M. Peters and Pall. B. Wathinit \\ Department of Internal Medicine. Unicersity of Michigan Medical Center. Ann Arbor. Michigan
}

\begin{abstract}
Progressive liver fibrosis in rats develops when they are fed a diet deficient in choline. This diet also results in a pronounced and selective decrease in the liver microsomal content of a phase I drug-metabolizing enzyme belonging to the cytochrome P-450III gene family. Because P-450III cytochromes characteristically catalyze the $\boldsymbol{N}$-demethylation of erythromycin, we believed that the production of breath $\mathrm{CO}_{2}$ from erythromycin would be dramatically reduced in choline-deficient rats. However, when 12 cholinedeficient rats were compared with 9 control rats, the reduction in $\mathrm{CO}_{2}$ production from erythromycin (mean decrease $71 \%$ ) was essentially identical to that from aminopyrine (mean decrease $69 \%$ ), a substrate believed to be metabolized normally by the hepatocyte in fibrotic liver disease. Furthermore, we found that the relative erythromycin and aminopyrine demethylase activities were comparable when measured in vitro in liver microsomes prepared from the choline-deficient rats. To determine the molecular basis for the erythromycin demethylase activity in the choline-deficient rats, the liver microsomes were subjected to immunoblot analysis using a variety of polyclonal and monoclonal antibodies capable of distinguishing individual P-450III-related proteins. Our studies confirm that a major erythromycin demethylase belonging to the P-450III family, termed P.450p, was greatly reduced in the choline-deficient rat liver. However, the specific concentration of a second P-450p-related protein was essentially normal and that of a third P-450p-related protein was actually increased in the choline-deficient rat liver. These changes occurred over weeks and months on the choline-deficient diet and are not consistent with "feminization" of the liver. The P.450p-related proteins appeared to catalyze erythromycin demethylase activity because antibodies recognizing them inhibited the majority $(62 \%)$ of this activity in choline-deficient rat microsomes. Finally,
\end{abstract}

Received January 26, 1990; accepted Jume 13, 1990

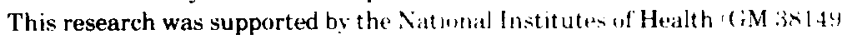
PBW 1 and the Veterans Administ ration

Drs. Kolars and Watkins are recipient - of Veterans Administration C'arrel Development Awards.

Address reprint requests to: Paul B Watkins, M.D. 65loD MSRB I University of Michigan Medical ('enter. 1150) West Medical ('enter I)rivt. Ann Arbor, Ml 48109-(0682.

$31 / 1 / 24802$
RNA extracted from choline-deficient rat livers was hybridized on Northern blots with synthetic oligonucleotide probes that identify the only two known rat P-450III cDNAs, PCN-1 and PCN-2. Prolonged choline deficiency appeared to have no consistent effects on expression of these RNA species. We conclude that despite the down-regulation of a major erythromycin demethylase, this catalytic activity is relatively preserved in the choline-deficient rat, at least in part because of differential regulation of P.450III cytochromes. Erythromycin therefore appears to offer little advantage over aminopyrine as a substrate for assessing liver function in this model of chronic liver disease. (Hrpatology 1990;12:1371-1378.)

The ability to metabolize many drugs is impaired in patients with cirrhosis. Based on this observation, it has heen proposed that the severity of chronic liver disease and cirrhosis can be quantitated in at least some patients by measuring their ability to metabolize a test dose of aminopyrine (reviewed in reference 1). Aminopyrine is demethylated in the liver by the mixed function oxidase system, which is made up of multiple families of genetically related enzymes collectively termed $(y-$ tochromes P-450. Because a large proportion of the carbon in the cleaved methyl group promptly appears in the breath as $\mathrm{CO}_{2}$, the ability to demethylate aminopyrine can be estimated in a patient simply as the rate of production of ${ }^{14} \mathrm{CO}_{2}$ in the breath after administration of a test dose of $\left[{ }^{1.4} \mathrm{C} \mathrm{N}\right.$-methyl] aminopyrine (2). Enthusiasm over the potential usefulness of the aminopyrine breath test has been tempered, however, by the observation that the result is influenced by many other concomitantly administered medications (reviewed in reference 1). Furthermore, ethanol consumption appears to increase the rate of production of $\mathrm{CO}_{2}$ from aminopyrine (3), presumably by inducing liver cytochromers) P-450 capable of demethylating aminopyrine. The breath test may therefore be difficult to interpret in the large population of patients with alcoholic liver disease.

We have recently described a breath test that uses erythromycin as a substrate (4). We believed that erythromycin might be preferable to aminopyrine as a substrate for assessing liver function for two reasons. First, the major erythromycin demethylases in liver 
have been identified and belong to the P-450III gene family (5). Because P-450III cytochromes have been reasonably well characterized in rat and man (6-13), medications likely to influence erythromycin demethylation are known $(4,6-12)$ and ethanol should have no effect $(13,14)$. Second, the available evidence suggested that in chronic liver disease and cirrhosis, the ability to demethylate erythromycin might be reduced to a greater extent than the ability to demethylate aminopyrine. Chronic liver disease appears to have differential effects on the regulation of individual cytochromes $\mathrm{P}-450$ and their corresponding catalytic activities (15-18). Moreover, Murray et al. (18) showed that the concentration of at least one major P-450III cytochrome was less than 5\% of normal in microsomes prepared from rats given fibrotic liver disease by prolonged choline deficiency. In the same microsomes, however, the concentrations of some other cytochrome $\mathrm{P}-\mathbf{4 5 0}$ proteins were essentially normal (18). This indicated that P-450III cytochromes may be selectively down-regulated in the fibrotic liver, which, in turn, would be expected to result in loss of the hepatocyte's intrinsic ability to demethylate erythromycin. On the other hand, Reichen et al. (19) have recently presented data suggesting that the hepatocyte's intrinsic ability to demethylate aminopyrine is not significantly altered in rats with fibrotic liver disease. These authors proposed that the reduced ability to demethylate a test dose of aminopyrine in chronic liver disease reflects only the reduced hepatocyte mass and the alterations in liver blood flow that characteristically accompany cirrhosis. Taken together, these observations suggested that the cytochromes P-450 involved in aminopyrine demethylation, which have not yet been identified, are probably present in near normal concentration in cirrhotic liver hepatocytes, whereas the concentration of forms primarily involved in erythromycin demethylation may be significantly decreased. Since reduction in hepatocyte mass and liver circulatory changes should have comparable effects on the metabolism of both substrates, we reasoned that there might be greater impairment in production of $\mathrm{CO}_{2}$ from erythromycin than from aminopyrine in rats with liver fibrosis. If so, the erythromycin breath test might provide a very sensitive parameter of liver function in chronic disease and cirrhosis.

To test this idea, we administered the erythromycin and aminopyrine breath tests to groups of rats given fibrotic liver disease by prolonged nutritional deficiency. Contrary to our expectation, we found that when these rats were compared with healthy rats, the fall in $\mathrm{CO}_{2}$ production from each substrate was essentially identical. To investigate the molecular basis for the relative preservation of P-450III catalytic activity, the diseased liver microsomes were analyzed using antibodies that are capable of distinguishing members of the P-450III gene family. We confirmed that a major liver P-450III protein is almost completely repressed in the cholinedeficient (CD) animals. However, the microsomal concentration of a second P-450III-related protein was unchanged and that of a third related protein was actually increased.

\section{MATERIALS AND METHODS}

Animals and Treatments. Male, Sprague-Dawley rats (80 to $100 \mathrm{gm}$ ) were obtained from Charles River, Inc., (Wilmington, $\mathrm{MA}$ ) and housed two to five per cage with free access to water. After acclimatization, rats had free access to either a custom high-fat, CD chow (ICN Nutritional Biochemicals Diet $\# 901387, \mathrm{ICN}$, Cleveland, $\mathrm{OH}$ ) that was free of methionine, folic acid, and vitamin $B_{12}$ (referred to as the "cholinedeficient" or "CD" diet) or an identical "control" chow supplemented with choline chloride $(165 \mathrm{mg} / 100 \mathrm{gm})$, methionine $(230 \mathrm{mg} / 100 \mathrm{gm})$, folic acid (198 $\mu \mathrm{g} / 100 \mathrm{gm})$ and vitamin $B_{12}(3 \mu \mathrm{g} / 100 \mathrm{gm})$ (referred to as the "control" diet). Rats in both groups gained weight, but at 7 mo rats on the CD diet weighed $45 \%$ less than rats on the control diet (mean 398 gm vs. $719 \mathrm{gm}$ ). After 2 wk to 7 mo on the diets, rats underwent breath tests and/or were killed by decapitation, and liver tissue assays were performed.

After the animals were decapitated, the liver was perfused through the hepatic vein with PBS, frozen in liquid nitrogen, and stored at $-70^{\circ} \mathrm{C}$. Hepatic hydroxyproline content was assayed as previously described (20) from 4 gm of liver tissue taken from the right lobe. Hepatic hydroxyproline was elevated an average of 2.2 -fold in livers of 13 rats maintained for $7 \mathrm{mo}$ on the CD diet relative to the livers of 9 rats maintained on the supplemented diet (4.02 vs. $1.81 \mu \mathrm{mol}$ hydroxyproline/gm liver; $\mathrm{p}<0.001$ according to an unpaired $t$ test). Histological examination revealed normal histology in a randomly selected supplemented control rat, whereas fatty infiltration and fibrosis were present in a randomly selected CD diet animal (not shown). These studies confirmed that significant liver fibrosis had occurred as a result of the CD diet. All studies were approved by the University of Michigan Committee on Animal Use.

Breath Tests. The erythromycin breath test (ERMBT) was performed essentially as described (4). Rats received tail vein injections of 0.5 to $1.0 \mu \mathrm{Ci} / 100 \mathrm{gm}$ body weight $\left[{ }^{14} \mathrm{C} \mathrm{N}\right.$-methyl] erythromycin (54.3 $\mathrm{mCi} / \mathrm{mmol}$, New England Nuclear Corp., Boston, MA) and did not concomitantly receive unlabeled erythromycin. Trace doses of erythromycin were used because the pharmacological doses given in prior studies (4) quickly killed the animals who had received the $C D$ diet. The aminopyrine breath test (APBT) was performed by injecting $0.5 \mu \mathrm{Ci} / 100 \mathrm{gm}$ body weight of $\left[{ }^{14} \mathrm{C}\right.$ dimethyl] aminopyrine (101.8 $\mathrm{mmol} / \mathrm{mCi}$, New England Nuclear Corp.) into the tail vein. After the tail vein injections, the rats were placed in a water-sealed polyurethane breath chamber and $\mathrm{CO}_{2}$ was collected at intervals and assayed for ${ }^{14} \mathrm{C}$ (4). The results of each breath test are expressed as the percent of injected ${ }^{14} \mathrm{C}$ recovered during the first hour after injection.

When both breath tests were performed on the same rats, the APBT was performed $24 \mathrm{hr}$ before the ERMBT. Initial studies (not shown) indicated that the administration of the APBT did not influence the results of the ERMBT when the tests were separated by $24 \mathrm{hr}$.

Microsomal Assays. The liver tissue remaining after hydroxyproline determination was used for preparation of microsomes by differential centrifugation (21). Up to $100 \mu \mathrm{g}$ of microsomal protein was then subjected to $10 \%$ SDS-PAGE, and the separated proteins were transferred to nitrocellulose sheets. The nitrocellulose sheets were then reacted with antibodies as previously described (22). The monoclonal antibodies $1 \mathrm{G} 8$ and $13-7-10$ have been previously characterized $(9,23)$ and were gifts from Dr. Philip Guzelian. The antibody used to recognize the ethanol-inducible cytochrome P-450j (P-450IIE1) was a gift from Dr. Minor J. Coon. Erythromycin demethylase and aminopyrine demethylase activities were determined in liver microsomes by the Nash 


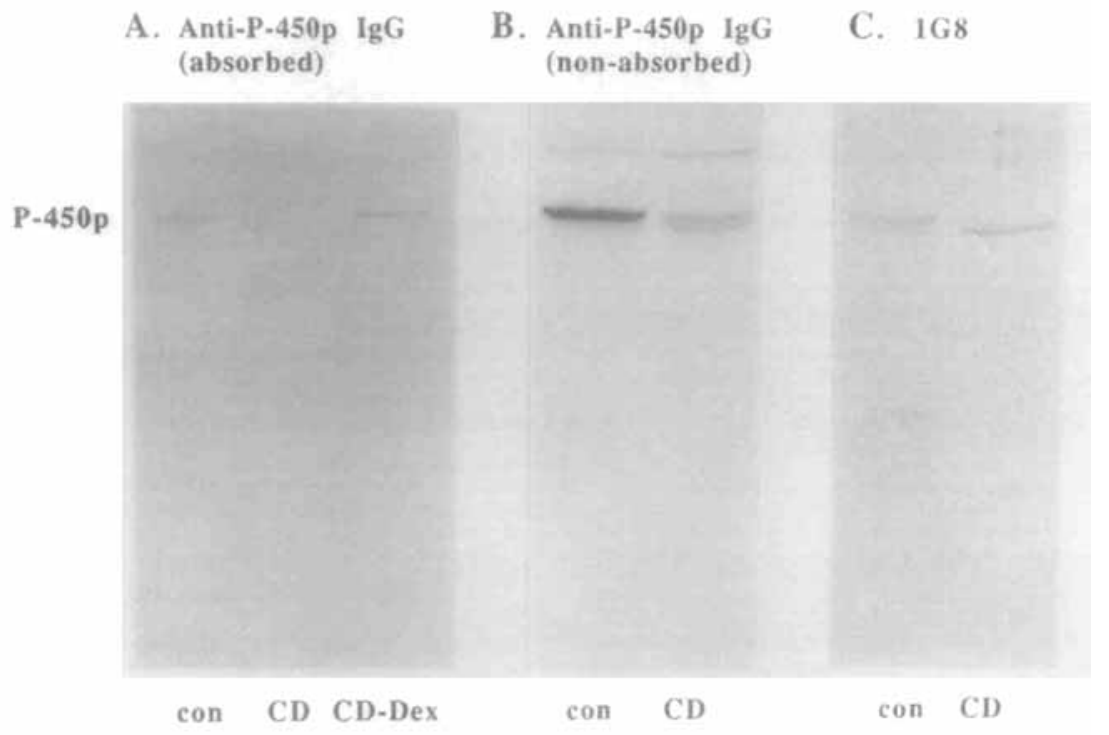

Fig. 1. P-450p-related proteins present in liver microsomes prepared from choline-deficient rats. Microsomes ( $100 \mu \mathrm{g}$ ) prepared from control (con) and choline-deficient ( $C D$ ) rats were subjected to SDS-PAGE, and the separated proteins were then transferred electrophoretically to the nitrocellulose sheets. The representative blots shown were developed with the indicated antibodies as described in "Materials and Methods." Two preparations of anti-P-450p IgG were used; one had been absorbed to female rat liver microsomes (A) and one had not (B). The slowly migrating protein identified only by the unabsorbed antibody (B) is unlikely to be a cytochrome P-450. 1G8 (C) is a monoclonal antibody previously shown to recognize P-450p (32). One CD rat had been pretreated with dexamethasone (CD-Dex).

reaction (7). Immunoinhibition of microsomal erythromycin demethylase activity was performed as previously described (8).

Hybridization Studies. 'Total RNA was isolated from liver tissue by the method of Chirgwin et al. (24), subjected to agarose gel electrophoresis and transferred to nitrocellulose paper. Hybridizations were performed with 30 -mer synthetic oligonucleotides corresponding to the hypervariable regions of two P-450IIIA cDNAs identified as PCN-1 and PCN-2 (25) (or P450IILA1 and P-450IILA2, respectively [5]). The hybridization conditions used have been previously determined to selectively identify either PCN-1 or PCN-2 mRNA on Northern blots (25). P-450IIE 1 mRNA was identified by hybridizing Northern blots with a P-450IIE-specific 30-mer synthetic oligonucleotide (26) under conditions previously shown to result in selective identification of P-450IIE1 mRNA (26).

\section{RESULTS}

Aminopyrine and Erythromycin Demethylase Activity. ERMBT and APBT were administered to CD and control rats. The production of $\mathrm{CO}_{2}$ from aminopyrine was diminished by approximately $70 \%$ in the $\mathrm{CD}$ rats compared with that observed in the controls (Table 1). This decrease is comparable to that previously reported in rats with established cirrhosis (19). When the ERMBT was administered, the production of $\mathrm{CO}_{2}$ from erythromycin was also reduced approximately $70 \%$ in the deficient rats (Table 1). Furthermore, in the rats that had received both breath tests, there was excellent correlation between the production of $\mathrm{CO}_{2}$ from each substrate ( $r=0.99$, data not shown). The comparable falls in the production of $\mathrm{CO}_{2}$ from aminopyrine and
TABLE 1. Results of APBT and ERMBT in rats on a control or CD diet

\begin{tabular}{|c|c|c|c|c|}
\hline \multirow[b]{2}{*}{ Diet } & \multicolumn{2}{|c|}{ APBT $^{\circ}$} & \multicolumn{2}{|c|}{ ERMBT $^{\alpha}$} \\
\hline & $\%$ & $\mathbf{n}$ & $\%$ & $\mathbf{n}$ \\
\hline Control & $17.5(2.2)$ & 4 & $7.2(1.1)$ & 9 \\
\hline CD & $5.5(1.7)$ & 9 & $2.1(0.7)$ & 12 \\
\hline Percent change & \multicolumn{2}{|c|}{-69} & \multicolumn{2}{|c|}{-71} \\
\hline
\end{tabular}

"Results expressed as percentage of administered ${ }^{14} \mathrm{C}$ exhaled in 1 hr. Numbers in parentheses represent standard deviations from the mean.

APBT = aminopyrine breath test; ERMBT = erythromycin breath test; $\mathrm{CD}=$ choline-deficient.

erythromycin did not support a selective loss of in vivo $\mathrm{P}-450$ III catalytic activity in the $\mathrm{CD}$ rats. However, it was possible that factors other than liver content of the responsible cytochromes $\mathrm{P}-450$ became rate limiting in the production of $\mathrm{CO}_{2}$ from these substrates in the $\mathrm{CD}$ rats.

We therefore directly examined whether erythromycin demethylase activity was selectively reduced in microsomes prepared from the liver of each CD rat. As shown in Table 2, the ability to demethylate aminopyrine in the $C D$ rat liver microsomes was approximately $50 \%$ of that seen in control microsomes. Comparable falls in microsomal aminopyrine demethylase activity have been reported previously in cirrhotic rats (19). Since the intrinsic ability of the hepatocyte to demethylate aminopyrine appears to be normal in the 
TABLE 2. Results of erythromycin demethylase activity and aminopyrine demethylase activity in liver microsomes from rats on a control or CD diet

\begin{tabular}{|c|c|c|c|c|}
\hline Diet & $\begin{array}{c}\text { ERMD } \\
(\mathrm{nmol} / \mathrm{min} / \mathrm{mg} \text { protein })^{b}\end{array}$ & $\begin{array}{c}\text { APD } \\
(\mathbf{n m o l} / \mathrm{min} / \mathbf{m g} \text { protein })^{b}\end{array}$ & $\begin{array}{c}\text { ERMD }^{a} \\
{\text { (nmol/min/liver })^{b}}^{b}\end{array}$ & $\begin{array}{c}\text { APD }^{a} \\
{\text { (nmol/min/liver })^{b}}^{b}\end{array}$ \\
\hline Control $(\mathrm{n}=9)$ & $1.19(.13)^{b}$ & $2.92(.38)$ & $363(64)$ & $888(144)$ \\
\hline $\mathrm{CD}(\mathrm{n}=13)$ & $0.89(.29)$ & $1.48(.23)$ & $256(85)$ & $425(101)$ \\
\hline Percent change & -25 & $-50^{r}$ & $-30^{r}$ & $-50^{\circ}$ \\
\hline
\end{tabular}

${ }^{a}$ Determined as (specific activity) $\times$ (microsomal protein from entire liver).

${ }^{h}$ Numbers in parentheses are standard deviations.

" $p<0.01$ determined by an unpaired $t$ test.

ERMD = erythromycin demethylase APD = aminopyrine demethylase; $\mathrm{CD}=$ choline deficient.

cirrhotic liver (19), the $50 \%$ decrease in specific activity may reflect dilution of the hepatocyte microsomes with those derived from other cell types (such as macrophages and bile ductular epithelia) that are abundant in the diseased liver.

The erythromycin demethylase activity was also significantly lower in the hepatic microsomes prepared from $\mathrm{CD}$ rats compared with control microsomes (Table 2). However, the fall in erythromycin demethylase activity was not greater than that in aminopyrine demethylase activity. This was also true when the respective demethylase activities were estimated for the entire liver (Table 2). Hence, the catalytic activity characteristic of P-450III appeared to be relatively preserved in the CD liver microsomes, an observation that seemed at odds with the report that at least one major P-450III protein should be virtually absent (18).

Immunochemical Analysis of Liver Microsomes. The liver microsomes prepared from each rat were analyzed on immunoblots to determine whether expression of P-450III cytochromes had in fact been repressed in the CD rats. Immunoblots were first developed with a polyclonal antibody that selectively recognizes a major rat liver P-450III cytochrome termed P-450p $(8,11)$. In uninduced rats, $\mathrm{P}-450 \mathrm{p}$ is generally detectable only in male liver $(9,11)$. The P-450p specific antibody we used was prepared by absorbing anti-P-450p IgG (goat) to liver microsomes prepared from a female rat (11). The absorption step removes antibodies that recognize epitopes common to P-450p and to other P450III proteins present in the female rat liver (9). As is shown in Figure 1A, P-450p was detected in the control liver microsomes but was barely detected, if at all, in the CD liver microsomes, essentially confirming the observations of Murray et al. (18). The repression of P-450p appeared to be a selective effect because there was no detectable difference between control and $C D$ microsomes in the content of immunoreactive P-450j (P-450IIE1) (data not shown). However, P-450p could still be induced in the CD rat by pretreatment with dexamethasone (Fig. 1A), indicating that the hepatocyte remained capable of expressing this enzyme. It therefore appeared that erythromycin demethylation was being catalyzed in the CD rat liver by enzymes other than P-450p.

It has recently been appreciated that rat liver contains multiple P-450III cytochromes $(9,25,27)$. We reasoned that P-450III cytochromes other than P-450p (and those not recognized by the absorbed polyclonal antibody to P-450p) might account for the relative preservation of erythromycin demethylase activity in the CD rat liver. Immunoblots of the rat liver microsomes were therefore developed with the unabsorbed anti-P-450p IgG, which would be expected to recognize multiple members of the P-450III gene family. As shown in Figure 1B, blots developed with the unabsorbed IgG confirmed that the concentration of P-450p had been greatly reduced in the CD microsomes. However, a second protein band was recognized by the unabsorbed antibody in the $C D$ microsomes, reflecting a protein that migrated more rapidly than did P-450p on the gels (Fig. 1B). To estimate the proportion of erythromycin demethylase activity that was being catalyzed by proteins recognized by this antibody, microsomes prepared from representative control and $C D$ rats were incubated with the anti-P-450p IgG or with nonimmune IgG $(10 \mathrm{mg} / \mathrm{nmol}$ spectrally determined $\mathrm{P}-450$ ) before measuring catalytic activity toward this substrate. Erythromycin demethylase activity was inhibited to a comparable extent in liver microsomes prepared from each animal $(54 \%$ and $62 \%$ inhibition in control and deficient microsomes, respectively, compared with the activity seen in the microsomes containing nonimmune IgG). We concluded that the proteins recognized by the nonabsorbed antiP-450p IgG catalyzed most erythromycin demethylase activity in the livers of both CD and control animals.

We next used monoclonal antibodies in an attempt to determine the identity of the P-450p-related protein that appeared to be induced in the CD liver microsomes. As shown in Figure 1C, the induced protein appeared to be recognized by a monoclonal antibody termed $1 \mathrm{G} 8$. $1 \mathrm{G} 8$ has been previously shown to recognize P-450p (9), and the absence of P-450p in the CD microsomes was also confirmed using this antibody (Fig. 1C). In addition, $1 \mathrm{G} 8$ recognizes a second protein that is male specific in uninduced rats, and this protein migrates slightly faster than P-450p on SDS-PAGE $(9,28)$. As shown in Figure 1C, $1 \mathrm{G} 8$ appeared to recognize the P-450p-related protein present in the $\mathrm{CD}$ microsomes, and this protein exactly comigrated with the faster migrating protein present in control liver microsomes (hereafter referred to as " $p 2$ "). 


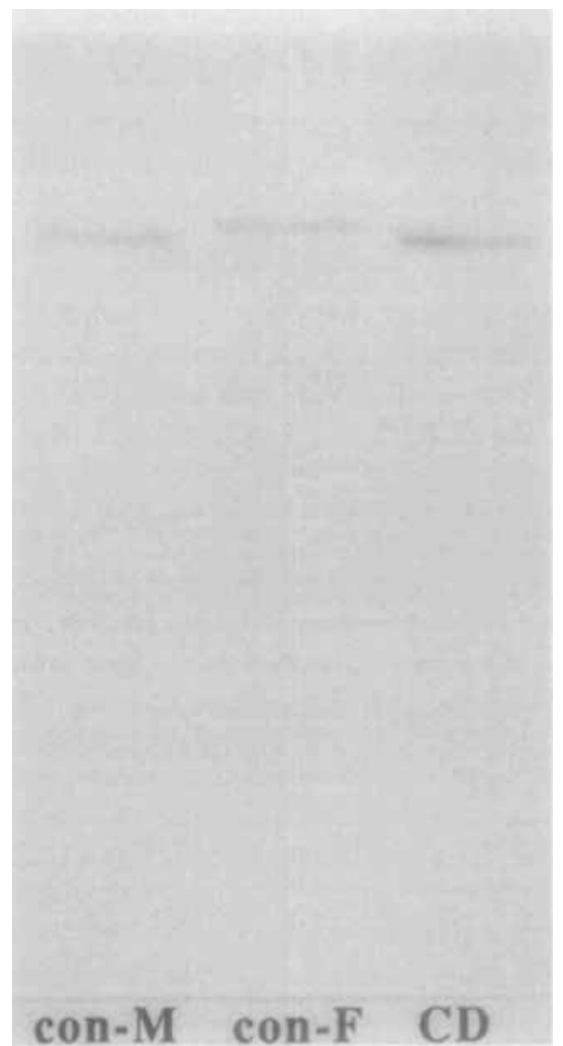

FIG. 2. Liver microsomes reacted with the monoclonal antibody 13-7-10. Liver microsomes prepared from control male (con-M), control female (con-F) and choline-deficient ( $C D$ ) male rats were subjected to SDS-PAGE $(40 \mu g)$. The separated proteins were transferred to nitrocellulose sheets and reacted with the monoclonal antibody 13-7-10 as described in "Materials and Methods."

Finally, the immunoblots were developed with another monoclonal antibody, termed 13-7-10, (23), that identifies additional P-450p-related proteins present in liver microsomes prepared from untreated male and female rats $(9,28)$. As shown in Figure 2 , the reactive protein present in untreated male liver migrates more rapidly on PAGE than does the female reactive protein, as has been previously reported $(9,28)$. It has been shown (9) that the 13-7-10 reactive protein present in control male liver microsomes exactly comigrates with p2. Liver microsomes prepared from our CD (male) rats contained a reactive protein indistinguishable from the male-specific 13-7-10 reactive protein on immunoblots (Fig. 2). In addition, the specific content of this immunoreactive protein appeared to be identical in microsomes prepared from either the CD or control rats (Fig. 2 and data not shown).

To see whether repression of P-450p and induction of the related protein were due to an immediate effect of the diet, rats were placed on the CD and control diets. Members of each treatment group were killed 2 wk later and at the end of each consecutive month on the diets. Microsomes prepared from each rat were analyzed on immunoblots developed with the monoclonal antibody

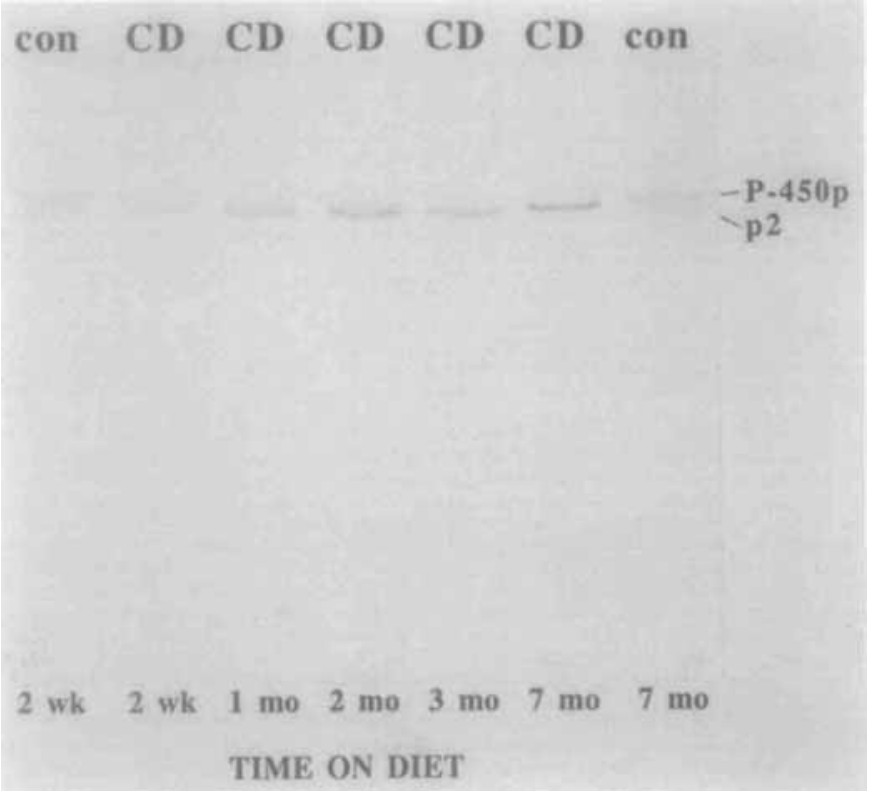

Fici. 3. The loss of immunoreactive P-450p and the appearance of an immunochemically related protein $(p 2)$ in liver microsomes as a function of time on the CD diet. Rats were killed after the indicated intervals on the control (con) or choline-deficient $(C D)$ diets. Liver microsomes were prepared and analyzed using $75 \mu \mathrm{g}$ microsomal protein and methods noted previously. Immunoblots were developed with the monoclonal antibody $1 \mathrm{G} 8$

1G8. As shown in Figure 3, the loss of immunoreactive P-450p and the induction of the related protein occurred gradually over time on the CD diet.

mRNA Studies. To date only two complete cDNAs corresponding to rat P-450III genes have been cloned and sequenced, and these have been termed PCN-1 and PCN-2 (25), which correspond to the genes P450IIIA1 and P450IIIA2, respectively (5). We sought to determine whether regulation of these mRNAs was altered in the $\mathrm{CD}$ rat. In addition, by comparing PCN-1 and PCN-2 mRNA content in control and CD rat livers, we hoped it would be possible to tentatively identify the P-450IIIrelated proteins recognized by our antibodies. This would, however, require that the loss of P-450p and the appearance of the P-450III-related protein (Fig. 3) had resulted in the $C D$ rat from alterations in regulation at steps before mRNA translation. Accordingly, total RNA extracted from the livers of control and CD rat livers was analyzed on Northern blots hybridized with 30-mer synthetic oligonucleotide probes corresponding to hypervariable regions of $\mathrm{PCN}-1$ and $\mathrm{PCN}-2$ cDNA (25). PCN-1 RNA has been reported to be inducible by dexamethasone but not to be readily detected in liver RNA prepared from control male or female rats (25). Our results confirmed these observations (Fig. 4). We also found that PCN-1 mRNA was undetectable in the livers from each of the CD rats (Fig. 4).

We found that PCN-2 mRNA was readily detected in male but not female liver and was not inducible by dexamethasone (Fig. 4); this confirms prior reports (25). 

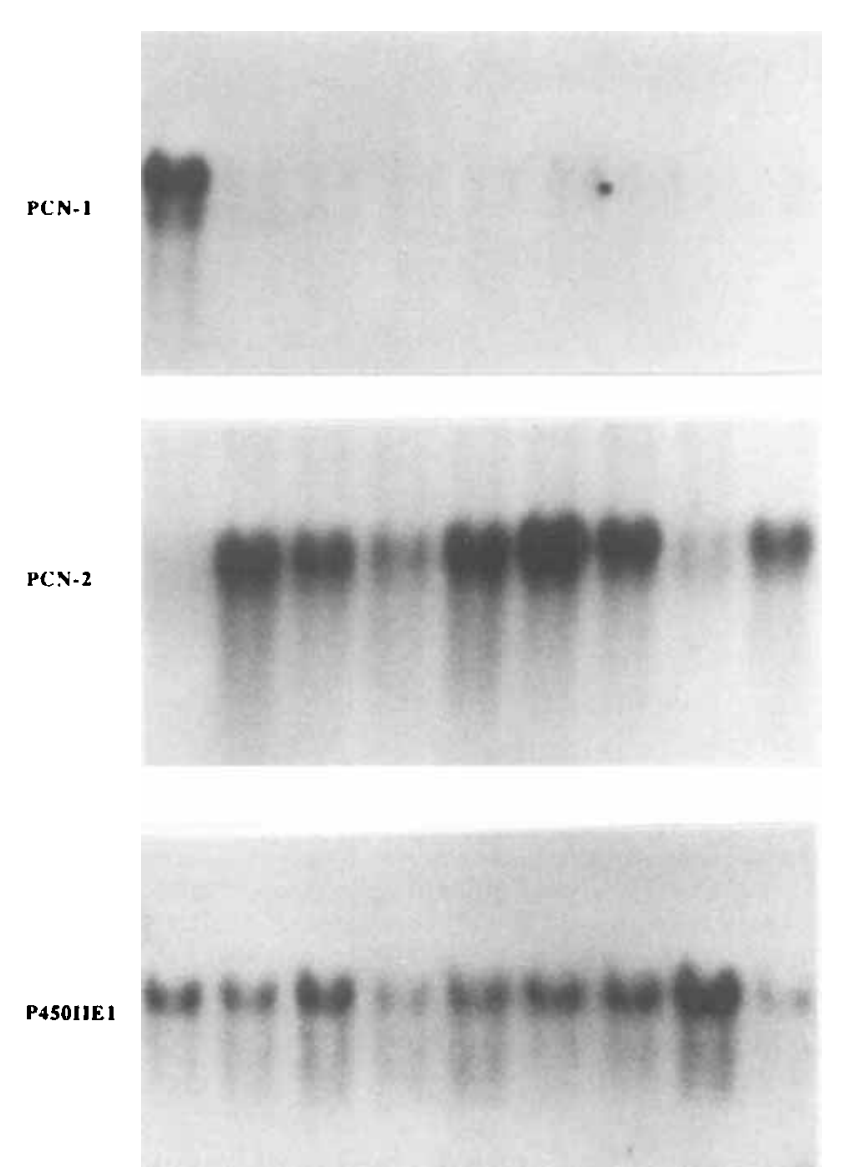

Dex-F Con-M CD Con-M CD Con-M CD Cun-F Con-M

Fic. 4. Identification of P-450III mRNAs in the livers of cholinedeficient rats. Total RNA was extracted from livers obtained from dexamethasone-pretreated female $(D E X-f)$, control male (Con-M), control female (Con-F) or choline-deficient male $(C D)$ rats as described in methods. The RNA $(10 \mu \mathrm{g})$ was subjected to agarose gel electrophoresis and then transferred to nitrocellulose sheets by capillary action. Shown above is an identical blot hybridized with each of the indicated 30-mer synthetic oligonucleotides. (The sheet was boiled between each hybridization). $\mathrm{PCN}-1$ and $\mathrm{PCN}-2$ are the only rat P-450III cDNAs that have been identified. To assure that comparable amounts of RNA were being analyzed from each rat, the blot was also hybridized with a synthetic oligonucleotide specific for P-450IIE1.

Among individual male liver RNA samples, the intensity of hybridization with the $\mathrm{PCN}-2$ probe varied remarkably (Fig. 4). However, there were no consistent differences in PCN-2 RNA concentrations between the $\mathrm{CD}$ and control liver RNA (Fig. 4). Moreover, when liver microsomes prepared from each of these rats were subjected to immunoblot analysis, there were no obvious correlations between the concentrations of any of the P-450p-related proteins and liver content of PCN-2 mRNA (data not shown). To assure that comparable amounts of mRNA from each rat had been analyzed, the blots were stripped and rehybridized with a 30-mer synthetic oligonucleotide specific for the ethanolinducible cytochrome P-450j (P-450IIE1) mRNA (26).
We observed generally higher amounts of P-450IIE1 mRNA in female than in male rats (Fig. 4 and data not shown), and this has been observed by others (14). No consistent differences in hybridization intensity were observed between the CD and control liver RNA samples (Fig. 4).

\section{DISCUSSION}

We have confirmed that the liver content of a major erythromycin demethylase (P-450p) is markedly reduced in a commonly used rat model for chronic liver disease (Figs. 1 and 3). Contrary to our initial hypothesis, however, the production of $\mathrm{CO}_{2}$ from erythromycin in these rats was not more significantly impaired than that from aminopyrine (Table 1). At least in part, this appears to result from relative preservation of erythromycin demethylase activity in the diseased liver (Table 2). Our observations are supported by those of Murray et al. (18), who reported that another catalytic activity characteristic of P-450III cytochromes (testosterone $6 \beta$-hydroxylase activity) also appeared to be relatively preserved in $\mathrm{CD}$ rat liver microsomes.

We believe that our immunochemical analysis of the CD liver microsomes provides an explanation for these observations. Although the concentration of $\mathrm{P}-450 \mathrm{p}$ was dramatically reduced in the $C D$ rat liver microsomes, the concentration of one P-450III-related protein appeared to be similar in control and CD rat liver microsomes (Fig. 2 ). Moreover, the microsomal concentration of another P-450III-related protein was markedly increased in the $\mathrm{CD}$ liver microsomes (Figs. 1 and 3). Because the non-P-450p proteins identified by the monoclonal antibodies have not yet been purified, it has not been possible to directly demonstrate that these proteins are capable of erythromycin demethylation. Nonetheless, most erythromycin demethylase activity in CD liver microsomes (essentially lacking $\mathrm{P}-450 \mathrm{p}$ ) could be inhibited by preincubation with anti-P $-450 \mathrm{p}$ IgG, indicating that most of this activity was due to $\mathrm{P}-450 \mathrm{p}-$-related proteins. Our observations suggest that the loss of erythromycin demethylase activity attributable to P-450p is compensated for by the induction of another P-450III cytochrome capable of catalyzing this reaction.

It should be pointed out that the reciprocal changes in the concentrations of $\mathrm{P}-450 \mathrm{p}$ and the second reactive protein (Fig. 3) might also be compatible with P-450p degradation to a slightly smaller protein in the CD liver. However, this seems unlikely for several reasons. First, both the unabsorbed and absorbed polyclonal antibody preparations appeared to have higher affinity for P-450p than for the second protein, whereas the reverse appeared to be the case with the monoclonal antibody $1 \mathrm{G} 8$ (Fig. 1). This suggests that $\mathrm{P}-450 \mathrm{p}$ contain multiple epitopes not present in the protein induced in the CD liver. Second, the CD rat hepatocytes were clearly capable of expressing P-450p when pretreated with dexamethasone (Fig. 1A). Finally, two attempts to purify the induced protein from our CD liver microsomes have failed using techniques similar to those used to purify P-450p (S. Wrighton, Personal communication, 1989). 
These observations suggest that the protein induced in the CD liver is related to, but structurally distinct from. P-450p. We believe that this is the first evidence to date that some cytochromes P-450 may actually be induced by chronic liver disease or prolonged nutritional deficiency.

Several conclusions can be drawn from our data about the mechanisms involved in the differential expression of P-450III proteins we observed in the CD animals. First, because the reciprocal changes in the specific concentrations of $\mathrm{P}-450 \mathrm{p}$ and the related protein were only evident after weeks on the diet (Fig. 3), they were not acute effects of the nutritional deficiency. However. since the CD rats gained weight much more slowly than did the controls, it is possible that starvation alone may account for the differential regulation we observed. Second, it is unlikely that the changes we observed reflect "feminization of the liver" as has been previously postulated (18). The CD rats appeared to maintain expression of a male-specific P-450III-related protein. and a related protein that is female-specific was never detected (Fig. 2). In addition, the P-450III-related protein that was induced in the CD liver was indistinguishable from a protein that is male specific in control animals (Figs. 1C and 3). Finally, the male-specific mRNA PCN-2, was readily detected in each CD rat liver (Fig. 4).

Our observations also supply some additional information regarding the P-450III gene family. When uninduced male rat liver microsomes are subjected to SDS-PAGE, the 13-7-10 reactive protein (Fig. 2) exactly comigrates with the faster migrating $1 \mathrm{G} 8$ reactive protein (9). It had therefore not been previously possible to show that these were distinct proteins rather than a single protein sharing both epitopes (9). In the CD liver. however, the IG8-reactive protein was significantly induced, whereas the microsomal concentration of the 13-7-10 reactive protein was unchanged, indicating that the proteins are not identical. Unfortunately, we were unable to use our rats to indicate whether any of the three immunoreactive proteins reflected expression of either the PCN-1 or PCN-2 gene. The concentrations of PCN-1 or PCN-2 mRNA did not appear to correlate well with the specific content of any of the P-450p-related proteins in the livers analyzed (Fig. 4). However, regulation of these proteins in the CD rats may not be at the level of transcription.

It is tempting to speculate that the loss of P-450p may have physiological significance in these animals. Selye (29) showed that rats pretreated with the prototypical inducer of P-450p, pregnenolone $16 \alpha$-carbonitrile, were resistant to the liver toxicity of many drugs. This appeared to result from an increased ability to detoxify and/or eliminate potential toxins. Furthermore, others have shown that pregnenolone $16 \alpha$-carbonitrile-treated rats are resistant to dimethylnitrosamine-induced hepatomas (30). The selective loss of P-450p in the CD rat may therefore result in decreased detoxification ability, which may contribute to the progressive liver injury associated with the diet. On the other hand, some
P-450III cytochromes appear to be involved in the bioactivation of various mycotoxins, including aflatoxin $B(31,32)$. Differential effects on regulation of P-450III cytochromes may therefore contribute to the high incidence of spontaneous hepatomas observed in rats maintained on the deficient diet for more than 7 mo (33). It has in fact been postulated that hepatomas observed in these rats result from enhanced susceptibility to aflatoxin present in trace amounts in the diet (34). Because the P-450IIE1 cytochrome has been widely implicated in carcinogenesis ( 14 and references therein), our incidental observations indicating that regulation of this enzyme did not appear to be altered in the CD rat liver may also be important.

Finally, it should not be concluded from our studies that the ERMBT will offer no advantage over the APBT in monitoring liver function in patients. Although P-450III cytochromes are highly conserved in mammals (7) and are major constitutive enzymes in human liver $(4,6)$, species differences in their regulation exist (7). Furthermore, the P-450III cytochromes have been characterized with regard to induction or inhibition by medications and are not induced by ethanol (6-14). The use of erythromycin therefore has theoretical advantages over aminopyrine where the responsible enzymes have yet to be identified. Clinical studies using the ERMBT are now underway.

\section{REFERENCES}

1. Baker AL, Kotake AN, Schoeller DA. Clinical utility of breath tests for the assessment of hepatic function. Semin Liver Dis 1983:3 318-329.

2. Hepner GW, Vesell ES. Assessment of aminopyrine metabolism in man by breath analysis after oral administration of ${ }^{14} \mathrm{C}$ aminopyrine. N Engl J Med 1974;291:1384-1388.

3. Lewis KO, Nicholson G, Lance P. Paton A. Aminopyrine breath test in alcohol liver disease and in patients on enzyme-inducing drugs. J Clin Pathol 1977;3:1040-1043.

4. Watkins PB, Murray SA, Winkelman LG, Heuman DM, Wrighton SA. Guzelian PS. Erythromycin breath test as an assay of glucocorticoid-inducible liver cytochromes P-450; studies in rats and patients. J Clin Invest 1989;83:688-697.

5. Nebert DW, Adesnik M, Coon MJ, Estabrook RW, Gonzalez FJ. Guengerich FP, Gunsalus IC, et al. The P-450 gene superfamily: recommended nomenclature. DNA 1987;6:1-11

6. Watkins PB, Wrighton SA, Maurel P, Schuetz EG, Mendez-Picon G, Parker GA, Guzelian PS. Identification of an inducible form of cytochrome P.450 in human liver. Proc Natl Acad Sci USA 1985:82:6310-6314.

7. Wrighton SA, Schuetz EG, Watkins PB, Maurel P, Barwick J Bailey BS, Hartle HT, et al. Demonstration in multiple species of inducible hepatic cytochromes P-450 and their mRNAs related to the glucocorticoid-inducible cytochrome P-450 of the rat. Molec Pharmacol 1985;28:312-321.

8. Wrighton SA, Maurel P, Schuetz EG, Watkins PB, Young B. Guzelian PS. Identification of the cytochrome P-450 induced by macrolide antibiotics in rat liver as the glucocorticoid-responsive cytochrome P-450p. Biochemistry 1985;24:2171-2178.

9. Hostetler KA, Wrighton SA, Guzelian PS. Immunochemical evidence for multiple steroid-inducible hepatic cytochromes $\mathbf{P}-450$ in the rat. Biochemistry $1987 ; 245: 27-33$.

10. Wrighton SA, Thomas PE, Willis P, Maines SL, Watkins PB, Levin W. Guzelian PS. Purification of a human liver cytochrome P-450 immunochemically related to several cytochromes $P-450$ purified from untreated rats. J Clin Invest 1987;80:1017-1022.

11. Elshourbagy NA, Guzelian PS. Separation, purification, and 
characterization of a novel form of hepatic cytochrome P-450 from rats treated with pregnenolone-16 $\alpha$-carbonitrile. $J$ Biol Chem 1980;255:1279-1285.

12. Guengerich FP, Martin MV, Beaunne PH, Kremers P, Wolff T, Waxman DJ. Characterization of rat and human liver microsomal cytochrome P-450 forms involved in nifedipine oxidation, a prototype for genetic polymorphism in oxidative drug metabolism. J Biol Chem 1986;261:5051-5060.

13. Wrighton SA, Thomas PE, Molowa DT, Haniu M, Shively JE, Maines SL, Watkins PB, et al. Characterization of ethanolinducible human liver $N$-nitrosodimethylamine demethylase. Biochemistry 1986;25:6731-6735.

14. Song B-J, Gelbion HV, Park S-S, Yang CS, Gonzalez FJ. Complementary DNA and protein sequences of ethanol-inducible rat and human cytochrome P-450s. J Biol Chem 1986;261:1668916697.

15. Murray M, Zaluzny L, Farrell GC. Drug metabolism in cirrhosis: selective changes in cytochrome P-450 isozymes in the cholinedeficient rat model. Biochem Pharmacol 1986;35:1817-1824.

16. Murray M, Cantrill E, Frost L, Mehta I, Farrell GC. Effects of long-term choline deficiency on hepatic microsomal cytochrome P-450-mediated steroid and xenobiotic hydroxylases in the female rat. Biochem Pharmacol 1988;37:1187-1192.

17. Murray M, Farrell GC. Different effects of carbon tetrachloride toxicity and cirrhosis on substrate binding to rat hepatic microsomal cytochrome P-450. Biochem Pharmacol 1984;33:687689.

18. Murray M, Zaluzny L, Dannan GA, Guengerich FP, Farrell GC. Altered regulation of cytochrome P-450 enzymes in cholinedeficient cirrhotic male rat liver: impaired regulation and activity of the male-specific androst-4-ene-3,17-dione 16 $\alpha$-hydroxylase, cytochrome P-450UT-A, in hepatic cirrhosis. Molec Pharmacol 1987;31:117-121.

19. Reichen J, Arts B, Schafroth U, Zimmermann A, Zeltner TB, Zysset T. Aminopyrine $N$-demethylation by rats with liver cirrhosis. Gastroenterology 1987;93:719-726.

20. Ruwart MJ, Rush BD, Snyder KF, Peters KM, Appelman HD, Henley KS. 16,16-Dimethyl prostaglandin E2 delays collagen formation in nutritional injury in rat liver. HePATOL.ori 1988;8:6164.

21. Van der Hoeven TA, Coon MJ. Preparation and properties of partially purified cytochrome P-450 and reduced nicotinamide adenine dinucleotide phosphate-cytochrome $P-450$ reductase from rabbit liver microsomes. J Biol Chem 1974;249:6302-6310.
22. Watkins PB, Wrighton SA, Schuetz EG, Maurel P, Guzelian PS Macrolide antibiotics inhibit the degradation of the glucocorticoidresponsive cytochrome $\mathrm{P}-450 \mathrm{p}$ in rat hepatocytes in vivo and in primary monolayer culture. J Biol Chem 1986;261:6264-6271.

23. Beaune P, Kremers P, Letawe-Gujon F, Gielen JE. Monoclonal antibodies against human liver cytochrome P-450. Biochem Pharmacol 1985;34:3547-3552.

24. Chirgwin JM, Przybyla AE, MacDonald RJ, Rutter WJ. Isolation of biologically active ribonucleic acid from sources enriched in ribonuclease. Biochemistry 1979;18:5294-5299.

25. Gonzalez FJ, Song B, Hardwick JP. Pregnenolone 16acarbonitrile-inducible P-450 gene family: gene conversion and differential regulation. Mol Cell Biol 1986;6:2969-2976.

26. Johansson I, Ekstöm G, Scholte B, Puzycki D, Jörnvall H, Ingelman-Sundberg M. Ethanol-, fasting-, and acetone-inducible cytochromes P-450 in rat liver: regulation and characteristics of enzymes belonging to the IIB and IIE gene subfamilies. Biochemistry 1988;27:1925-1934.

27. Halpert JR. Multiplicity of steroid-inducible cytochromes P-450 in rat liver microsomes. Arch Biochem Biophys 1988;263:59-68.

28. Watkins PB, Wrighton SA, Schuetz EG, Molowa DT, Guzelian PS. Identification of glucocorticoid-inducible cytochromes P-450 in the intestinal mucosa of rats and man. J Clin Invest 1987;80: 1029-1036.

29. Selye H. Hormones and resistance. J Pharmacol Sci 1971;60:1-28.

30. Argus MF, Hoch-ligeti C, Arcos JC, Conney AH. Differential effects of beta-naphthoflavone and pregnenolone-16 $\alpha$-carbonitrile on dimethylnitrosamine-induced hepatocarcinogenesis. J Natl Cancer Inst 1978;61:441-449.

31. Shimada Y, Guengerich FP. Evidence for cytochrome P-450nf, the nifedipine oxidase, being the principal enzyme involved in the bioactivation of aflatoxins in human liver. Proc Natl Acad Sci USA 1989;86:462-465.

32. Halvorson MR, Safe SH, Parkinson A, Phillips TD. Aflatoxin B1 hydroxylation by the pregnenolone-16 $\alpha$-carbonitrile-inducible form of rat liver microsomal cytochrome P-450. Carcinogenesis 1988;9:2103-2108.

33. Copeland DH, Salmon WD. The occurrence of neoplasms in liver, lung and other tissues of rats as a result of prolonged chronic deficiency. Am J Pathol 1946;22:1059-1079.

34. Salmon WD, Copeland DH. Occurrence of hepatomas in rats fed diets containing peanut meal as a major source of protein. Cancer Res 1963;23:571-576. 